\title{
ESTUDOS SOBRE A HISTÓRIA DA FORMAÇÃO E PRÁTICA DOCENTE DE EDUCAÇÃO FÍSICA: O ESTADO DA QUESTÃO
}

\author{
P. R. DE LIMA ${ }^{1}$, S. M. NÓBREGA-THERRIEN \\ Universidade Estadual do Ceará \\ ORCID ID: https://orcid.org/0000-0002-2323-40 \\ progerio.sport@gmail.com ${ }^{1}$
}

Submetido 28/04/2019 - Aceito 19/08/2020

DOI: $10.15628 /$ holos. 2020.8565

\section{RESUMO}

Este artigo apresenta a construção do Estado da Questão (EQ) que objetivou analisar as produções científicas publicizadas relacionadas à história da Educação Física com ênfase na formação e prática docente. De modo mais específico, procuramos conhecer a forma que os pesquisadores têm abordado seus estudos, evidenciar os objetivos, as fontes metodológicas e resultados das pesquisas definidas como achados e, apontar as possíveis lacunas de conhecimentos em relação à temática de investigação. O mapeamento dos estudos foi realizado no portal de periódicos da Scientific Electronic Library Online (SciELO) e na Biblioteca Digital Brasileira de Teses e Dissertações (BDTD) nos meses de setembro e outubro de 2018, utilizando-se como principais descritores
\end{abstract}

formação, prática docente, Educação Física e história, em algumas combinações. Constatamos a riqueza de olhares dos pesquisadores nos textos analisados, que nos permitiu conhecer diversas realidades e as maneiras que foram investigadas. Apontamos como principal lacuna a falta de estudos historiográficos da Educação Física que apresente como lócus municípios interioranos do Ceará. Por fim, consideramos que as reflexões e discussões contidas nesse estudo, podem auxiliar os pesquisadores no desenvolvimento de suas pesquisas a partir do interesse em saber e realizar o EQ sobre seu objeto de investigação, para melhor conhecê-lo e delimitá-lo de forma mais incisiva.

PALAVRAS-CHAVE: Estado da Questão, Educação Física, História, formação, prática docente.

\section{STUDIES ABOUT THE HISTORY OF THE TEACHER PRACTICE AND FORMATION OF PHYSICAL EDUCATION: THE STATE OF THE QUESTION}

\begin{abstract}
This article presents the construction of the State of the Question (SQ) that aimed to analyze the publicized scientific productions related to Physical Education history with emphasis in the teacher practice and formation. More specifically, we search to know the way that researchers have approached their studies, to evidence their objectives, the methodological sources and results of the researches defined as findings and, to point out the possible lacunas of knowledge about the thematic of investigation. The mapping of the studies was realized on the journals portal of the Scientific Electronic Library Online (SciELO) and in the Brazilian Digital Library of Theses and Dissertations (BDLTD) from
\end{abstract}

September to October of 2018, using as main descriptors formation, teacher practice, Physical Education and history, in some combinations. We verify the richness of researchers' views in the analyzed texts, that made possible for us to know diverse realities and the ways that were investigated. We point out as main lacuna the lack of historiographic studies of the Physical Education that presents as locus interior towns of Ceará. Lastly, we consider that the reflections and discussions in this study, can help researchers in the development of their researches from interest to know and realize the SQ about their investigation object, to get to know it better and delimit it more sharply.

KEYWORDS: State of the Question, Physical Education, History, formation, teaching practice. 


\section{INTRODUÇÃO}

Este estudo apresenta a construção do Estado da Questão (EQ) sobre a história da Educação Física com ênfase na formação e prática docente. Esse EQ foi realizado como parte da pesquisa desenvolvida para a elaboração da dissertação de mestrado intitulada de " $A$ história da Educação Física no município de Icó-CE: (re)constituição da prática docente nas escolas (19461983)" do Programa de Pós-Graduação em Educação (PPGE) da Universidade Estadual do Ceará (UECE).

Nessa perspectiva, buscando uma maior aproximação com as produções científicas publicadas e uma melhor compreensão da temática de pesquisa definida para desenvolvimento da referida dissertação, para realização de nosso EQ, partimos do seguinte questionamento: Quais são os estudos publicados sobre a história da Educação Física com ênfase na formação e prática docente?

A partir dessa indagação, nosso EQ objetivou analisar as produções científicas publicizadas relacionadas à história da Educação Física com ênfase na formação e prática docente. De modo mais específico, buscamos conhecer a forma que os pesquisadores têm abordado seus estudos, evidenciar os objetivos, as fontes metodológicas e os resultados das pesquisas definidas como achados e, apontar as possíveis lacunas de conhecimentos em relação à temática de investigação.

Compreendendo a complexidade que seria realizar esse levantamento de estudos nas diversas bases de armazenamento de dados de produção do conhecimento acadêmico-científico, definimos para nosso EQ, a utilização do portal de periódicos da Scientific Electronic Library Online (SciELO) e da Biblioteca Digital Brasileira de Teses e Dissertações (BDTD) para a realização do mapeamento dos trabalhos, que ocorreu no período de setembro a outubro de 2018, com a utilização dos descritores formação, prática docente, Educação Física e história, em algumas combinações detalhadas a posteriori.

Este estudo se torna relevante para os pesquisadores com interesse na história da Educação Física pelo mapeamento e discussões dos estudos, mas em especial, para os que desejam compreender o $\mathrm{EQ}$, pois o mesmo possibilita a ampliação da visão e concepções em relação aos temas investigados e clareza das contribuições das pesquisas para o meio científico, especificamente para área de conhecimento de vinculação do objeto. Diante disso, esperamos que as informações, reflexões e discussões presentes nesse texto, possam auxiliar o pesquisador interessado em conhecer e realizar o EQ sobre seu objeto de investigação.

Organizamos esse artigo, contemplando inicialmente a introdução, na qual destacamos a problemática, objetivos e relevância da pesquisa, depois disso, tecemos algumas considerações sobre a importância do Estado da Questão, em seguida, apresentamos os procedimentos metodológicos do estudo. Logo depois, apontamos as análises e discussões dos resultados, finalizando com as considerações finais, em que reforçamos as principais constatações e realizamos as reflexões conclusivas. 


\section{REFLETINDO SOBRE A IMPORTÂNCIA DO ESTADO DA QUESTÃO}

O mapeamento dos estudos científicos nos permite conhecer as produções existentes no campo da ciência sobre uma temática investigada, desvelando os principais focos, os referenciais teóricos em que se ancoram, as metodologias utilizadas e os resultados que se alcançam. Para Nóbrega- Therrien e Therrien (2010, p. 34) o Estado da Questão (EQ) tem como finalidade:

[...] levar o pesquisador a registrar, com suporte em um rigoroso levantamento bibliográfico, como se encontra o tema ou o objeto de sua investigação no estado atual da ciência ao seu alcance. Sua finalidade também é a de contribuir para o rigor científico e a criticidade no mergulho bibliográfico realizado pelo estudante/pesquisador, de modo a evitar vieses na construção das categorias teóricas e empíricas que vão ser trabalhadas por ele na revisão de literatura.

Percebemos que o EQ é um caminho que contribui, a partir dos achados, para a efetivação e desenvolvimento da temática de pesquisa, uma vez que ao mergulharmos nas análises dos dados advindos do inventário realizado, podemos obter um conhecimento mais incisivo sobre o objeto de investigação.

Assim, ao analisar o mapeamento de estudos, podemos constatar com rigor científico, como o objeto de pesquisa tem sido investigado. Esse levantamento, ainda permite descobrir outras categorias teóricas, além de validar aquelas que o estudo já traz a priori. Seguindo esse caminho, ao nos depararmos com os achados, numa análise minuciosa, podemos evidenciar categorias inerentes ao objeto para elaboração de uma fundamentação teórica coerente e coesa com a temática da pesquisa. Corroborando essa discussão, Nóbrega-Therrien e Therrien (2010, p. 35) mencionam que

A concepção proposta de EQ requer uma compreensão ampla da problemática em foco fundada nos registros dos achados científicos e nas suas bases teórico-metodológicas acerca da temática. Desse mergulho decorre igualmente a contribuição do próprio estudante/pesquisador, cuja argumentação, lógica, sensibilidade, criatividade e intuição delimitam as dimensões da nova investigação. É precisamente esse processo e o material/texto produzido nesta fase pelo pesquisador que fornecem os elementos para identificar e definir os referenciais e as categorias (a chamada base teórica) imprescindíveis à análise dos dados no enfoque pretendido.

Destacamos do trecho acima, a importância do papel do pesquisador para desenvolvimento do EQ, necessitando de habilidades inerentes para realizar as buscas e diante do que foi encontrado, ter desenvoltura para articular sua análise. Dito de outra forma, precisa-se de competência para conduzir todo processo, desde a elaboração dos critérios para procura dos estudos, posteriormente a organização e a análise dos achados, visando evidenciar suas contribuições, descobrindo nesse caminhar elementos para delimitação de seu objeto de investigação.

Nessa perspectiva, reafirmamos, que se faz necessário habilidade e competência do pesquisador para trabalhar a literatura selecionada, sendo conhecedor das ideias que fundamentam os autores dos referidos estudos, exigindo também capacidade para nesse processo 
ir tecendo a elaboração de seu texto, para não transparecer um amontoado de informações e conhecimentos desconectados.

Esse processo de elaboração do EQ permite um desenvolvimento profissional significativo ao pesquisador, por proporcionar confronto crítico das ideias dos autores encontrados nos trabalhos mapeados, constatação de olhares plurais e compreensões epistemológicas divergentes, entendimento das complexidades na abordagem da temática, e a contribuição dos debates sobre a multirreferencialidade (Nóbrega-Therrien \& Therrien, 2010).

Para realização do nosso $E Q$, definimos a busca pelas produções científicas sobre a temática que envolve a história da formação e prática docente de Educação Física, em periódicos no portal da SciELO e em dissertações e teses na BDTD. Caminho que apresentamos a seguir.

\section{PROCEDIMENTOS TEÓRICOS METODOLÓGICOS}

Ao realizar a busca de periódicos científicos no portal da SciELO, notamos que os trabalhos nesse ambiente, se apresentam distribuídos por revista. Os descritores utilizados para a busca foram: história, formação, prática pedagógica, prática docente, Educação Física, nordeste e Ceará, empregados em combinações.

A consulta no portal da SciELO aconteceu no mês de setembro de 2018. Nesse processo, utilizamos como filtro a marcação da opção todos os índices (isso corresponde ao ano, autor, financiador, resumo e título). No tocante a delimitação do idioma, selecionamos o português. Assim, a opção que fizemos por trabalhar com os periódicos brasileiros, teve o intuito de conhecermos a realidade nacional. O Quadro 1 mostra as combinações de descritores e booleanos utilizados e os resultados encontrados.

Quadro 1: Combinações de descritores e booleanos utilizados na pesquisa e resultado obtidos no portal da SciELO. Fortaleza/CE, 2018.

\begin{tabular}{|c|c|c|c|}
\hline Combinação de descritores e booleanos & $\begin{array}{c}\text { Resultado } \\
\text { Geral }\end{array}$ & Brasil & $\begin{array}{c}\text { Idioma } \\
\text { Português }\end{array}$ \\
\hline história AND Educação Física & 194 & 171 & 158 \\
\hline história AND Educação Física AND nordeste & - & - & - \\
\hline história AND Educação Física AND Ceará & - & - & - \\
\hline formação AND Educação Física & 458 & 371 & 342 \\
\hline formação AND Educação Física AND história & 37 & 31 & 29 \\
\hline prática pedagógica AND Educação Física & 63 & 57 & 52 \\
\hline prática pedagógica AND Educação Física AND história & 2 & 1 & 1 \\
\hline
\end{tabular}

Fonte: Elaboração própria.

Com obtenção desses dados, optamos por analisar os artigos identificados com a combinação que envolveu a categoria história. Assim, dos 194 artigos encontrados com história AND Educação Física obtivemos 4 achados, dos 37 com formação AND Educação Física AND história ficaram 6 achados e, os 2 artigos descobertos com prática pedagógica AND Educação Física AND história foram descartados. Esses artigos foram selecionados por apresentarem elementos históricos com demarcações de períodos (anos) e aspectos de (re)constituição histórica relacionados a Educação Física com implicações nos processos formativos e/ou práticas docentes, 
após inicialmente, realizarmos inferência no título e, posteriormente, leituras e análises dos resumos. Ressaltamos também, que os artigos selecionados obedeceram à classificação Qualis Capes (quadriênio 2013-2016) do periódico no mínimo B4 em Educação e Educação Física. O Quadro 2 a seguir apresenta os achados da pesquisa no portal da SciELO, com aproximação da temática de interesse.

Quadro 2: Periódicos científicos sobre história da Educação Física, ordenados por Revista, ano de publicação, título e autor. Fortaleza/CE, 2018.

\begin{tabular}{|c|c|c|c|}
\hline Revista & Ano $^{1}$ & Autor & Titulo \\
\hline $\begin{array}{ll}\text { Educação } & \text { e } \\
\text { Pesquisa (USP) } & \end{array}$ & 2002 & OLIVEIRA & $\begin{array}{l}\text { Educação Física escolar e ditadura militar no Brasil } \\
\text { (1968-1984): história e historiografia. }\end{array}$ \\
\hline $\begin{array}{l}\text { Educar em Revista } \\
\text { (UFPR) }\end{array}$ & 2009 & $\begin{array}{l}\text { BOMBASSARO; } \\
\text { VAZ }\end{array}$ & $\begin{array}{l}\text { Sobre a formação de professores para a disciplina } \\
\text { Educação Física em Santa Catarina (1937-1945): } \\
\text { ciência, controle e ludicidade na educação dos corpos. }\end{array}$ \\
\hline $\begin{array}{l}\text { Educar em Revista } \\
\text { (UFPR) }\end{array}$ & 2009 & $\begin{array}{l}\text { OLIVEIRA; } \\
\text { CHAVES JÚNIOR }\end{array}$ & $\begin{array}{l}\text { Os espaços para a educação física no ensino } \\
\text { secundário paranaense: um estudo comparativo entre } \\
\text { os anos finais da ditadura varguista e os anos da } \\
\text { ditadura militar brasileira pós } 1964 \text {. }\end{array}$ \\
\hline $\begin{array}{lr}\text { Revista } & \text { da } \\
\text { Educação } & \text { Física } \\
\text { (UEM) } & \\
\end{array}$ & 2012 & REI; LU & $\begin{array}{l}\text { Educação Física Escolar e Ditadura Militar no Brasil } \\
\text { (1964-1985): balanço histórico e novas perspectivas. }\end{array}$ \\
\hline $\begin{array}{l}\text { Motriz: } \text { Revista de } \\
\text { Educação } \quad \text { Física } \\
\text { (UNESP) }\end{array}$ & 2012 & $\begin{array}{l}\text { GÓIS JUNIOR; } \\
\text { PICCOLO; DIAS; } \\
\text { TEIXEIRA; } \\
\text { FREITA; SOUZA }\end{array}$ & $\begin{array}{l}\text { Estudo histórico sobre a formação profissional na } \\
\text { Escola de Educação Física e Esporte da Universidade } \\
\text { de São Paulo (1980-1990). }\end{array}$ \\
\hline $\begin{array}{l}\text { Revista Brasileira } \\
\text { de Educação Física } \\
\text { e Esporte (USP) }\end{array}$ & 2014 & DIAS & $\begin{array}{l}\text { Momentos iniciais da educação física em Goiás (1917- } \\
\text { 1929). }\end{array}$ \\
\hline $\begin{array}{l}\text { Revista Brasileira } \\
\text { de Educação Física } \\
\text { e Esporte (USP) }\end{array}$ & 2014 & $\begin{array}{l}\text { COSTA; } \\
\text { SANTOS; } \\
\text { GÓIS JUNIOR }\end{array}$ & $\begin{array}{l}\text { O discurso médico e a Educação Física nas escolas } \\
\text { (Brasil, século XIX). }\end{array}$ \\
\hline $\begin{array}{l}\text { História, Ciência, } \\
\text { saúde- } \\
\text { Manguinhos. } \\
\text { (FIOCRUZ) }\end{array}$ & 2014 & MELO; PERES & $\begin{array}{l}\text { O corpo da nação: posicionamentos governamentais } \\
\text { sobre a educação física no Brasil monárquico. }\end{array}$ \\
\hline $\begin{array}{l}\text { Revista Brasileira } \\
\text { de Educação (RBE) }\end{array}$ & 2018 & $\begin{array}{l}\text { LYRA; MAZO; } \\
\text { BEGOSSI }\end{array}$ & $\begin{array}{l}\text { A educação física no currículo da formação de } \\
\text { professores primários no Rio Grande do Sul (1877- } \\
\text { 1927). }\end{array}$ \\
\hline $\begin{array}{ll}\text { Cadernos } & \text { CEDES } \\
\text { (UNICAMP) }\end{array}$ & 2018 & SÁ & $\begin{array}{l}\text { A educação dos corpos infantis no projeto mato- } \\
\text { grossense de formação do cidadão republicano (1910- } \\
\text { 1930). }\end{array}$ \\
\hline
\end{tabular}

Fonte: Elaboração própria

Procurando expandir a busca em outros bancos de dados, realizamos o mapeamento das produções científicas no portal da Biblioteca Digital Brasileira de Teses e Dissertações (BDTD). A busca aconteceu durante o mês de outubro de 2018. Os descritores que utilizamos foram história, Educação Física, formação, formação docente, prática pedagógica, formação de professores, em

\footnotetext{
${ }^{1}$ Não utilizamos o filtro determinando ano por se tratar de uma pesquisa de caráter histórico.
} 
algumas combinações articuladas com o booleano AND. O Quadro 3 mostra a síntese dessa busca avançada.

Quadro 3: Síntese da busca avançada com combinação de descritores e resultados obtidos no portal da BDTD. Fortaleza/CE, 2018.

\begin{tabular}{|l|c|c|c|}
\hline \multirow{2}{*}{ Combinação de descritores e booleanos } & \multicolumn{3}{c|}{ Resultados } \\
\cline { 2 - 4 } & Dissertações & Teses & Total \\
\hline história AND Educação Física & 37 & 13 & 50 \\
\hline formação AND Educação Física AND história & 5 & 5 & 10 \\
\hline formação docente AND Educação Física AND história & 3 & 0 & 3 \\
\hline formação de professores AND Educação Física AND história & 2 & 1 & 3 \\
\hline prática pedagógica AND Educação Física AND história & 1 & 0 & 1 \\
\hline
\end{tabular}

Fonte: Elaboração própria.

Começamos a seleção pelo título, separando os trabalhos que se caracterizavam pela reconstituição da histórica da Educação Física em meio escolar, independente da existência de recorte temporal. Depois disso, fizemos a leitura dos resumos com foco nos objetivos, fontes utilizadas e principais resultados.

Após esses procedimentos, podemos destacar que dos 50 trabalhos obtidos como resultado geral, tivemos 13 achados, que correspondem a $26 \%$, um número que representa mais de um quarto do levantamento inicial. Ressaltamos também, que diante dos achados há uma concentração maior de dissertações, constando oito delas, sendo que teses foram encontradas cinco. No Quadro 4 enfatizamos as produções científicas que apresentaram relação com o objeto de investigação.

Quadro 4 - (Dissertações e teses) Instituições, ano de publicação, autor e título dos achados. Fortaleza/CE, 2018.

\begin{tabular}{|c|c|c|c|}
\hline \multicolumn{4}{|r|}{ Dissertações } \\
\hline Instituição & Ano & Autor & Título \\
\hline UNICAMP & 1996 & $\begin{array}{l}\text { Victor Andrade de } \\
\text { Melo }\end{array}$ & $\begin{array}{l}\text { Escola Nacional de Educação Física e Desportos - Uma possível } \\
\text { história. }\end{array}$ \\
\hline UFMG & 2007 & $\begin{array}{l}\text { Marcos Antônio } \\
\text { Almeida Campos }\end{array}$ & $\begin{array}{l}\text { Histórias entrelaçadas: presença da dança na Escola de } \\
\text { Educação Física da Universidade Federal de Minas Gerais (1952- } \\
\text { 1977). }\end{array}$ \\
\hline UFPE & 2009 & $\begin{array}{l}\text { Júlio Ricardo de } \\
\text { Barros Rodrigues }\end{array}$ & $\begin{array}{l}\text { A Educação Física como disciplina escolar... Que história é essa? } \\
\text { A construção do componente curricular Educação Física no } \\
\text { Colégio de Aplicação da Universidade Federal de Pernambuco } \\
\text { no período entre } 1971 \text { e } 2001 \text {. }\end{array}$ \\
\hline UFES & 2012 & $\begin{array}{l}\text { Antonio Sergio } \\
\text { Francisco Oliveira }\end{array}$ & Inezil Penna Marinho: História e Educação Física (1940 a 1958). \\
\hline UFES & 2012 & Tatiane Borel & $\begin{array}{l}\text { Processos de formação e práticas docentes na constituição } \\
\text { histórica da Educação Física Escolar no Espírito Santos, nas } \\
\text { décadas de } 1930 \text { e } 1940 \text {. }\end{array}$ \\
\hline UFS & 2016 & $\begin{array}{ll}\text { Mariza } & \text { Alves } \\
\text { Guimarães } & \end{array}$ & $\begin{array}{l}\text { Um olhar sobre a história da organização curricular da Educação } \\
\text { Física no Colégio de aplicação da Universidade Federal de } \\
\text { Sergipe (1959-1996). }\end{array}$ \\
\hline UNESP & 2016 & $\begin{array}{l}\text { Pedro Lucas dos } \\
\text { Santos Pêgo }\end{array}$ & $\begin{array}{l}\text { A história da graduação em Educação Física da UNESP de Bauru } \\
\text { e memória da reestruturação curricular de } 1990 \text {. }\end{array}$ \\
\hline
\end{tabular}




\begin{tabular}{|l|l|l|l|}
\hline UFSCar & 2016 & $\begin{array}{l}\text { Ribamar Nogueira } \\
\text { da Silva }\end{array}$ & $\begin{array}{l}\text { Currículo escrito e a história da Educação Física no Brasil (1896- } \\
1945) .\end{array}$ \\
\hline UNICAMP & 1994 & $\begin{array}{l}\text { Eustáquia } \\
\text { Salvadora } \\
\text { Sousa }\end{array}$ & $\begin{array}{l}\text { Teses } \\
\text { Meninos, a marcha! Meninas, a sombra! A História do Ensino da } \\
\text { Educação Física em Belo Horizonte (1897 a 1994). }\end{array}$ \\
\hline UNICAMP & 2005 & $\begin{array}{l}\text { Margareth } \\
\text { Anderáos }\end{array}$ & $\begin{array}{l}\text { A reorganização da formação profissional em Educação Física } \\
\text { no Brasil: Aspectos Históricos Significativos. }\end{array}$ \\
\hline UFBA & 2007 & $\begin{array}{l}\text { Roberto Gondim } \\
\text { Pires }\end{array}$ & $\begin{array}{l}\text { História da Educação Física na Bahia: o percurso da formação } \\
\text { profissional. }\end{array}$ \\
\hline UFC & 2008 & Ariza Maria Rocha & $\begin{array}{l}\text { Educação Física escolar: história da inserção e consolidação na } \\
\text { capital cearense. }\end{array}$ \\
\hline $\begin{array}{l}\text { PUC- } \\
\text { Goiás }\end{array}$ & 2010 & $\begin{array}{l}\text { Paulo Roberto } \\
\text { Veloso Ventura }\end{array}$ & $\begin{array}{l}\text { A Educação Física e sua constituição histórica: Desvelando } \\
\text { Ocultamentos. }\end{array}$ \\
\hline
\end{tabular}

Fonte: Elaboração Própria.

No próximo tópico, analisamos mais detalhadamente os achados da pesquisa, considerando artigos, dissertações e teses.

\section{ANÁLISES E DISCUSSÕES DOS RESULTADOS}

A discussão sobre os achados foi organizada iniciando pelos trabalhos científicos mais antigos considerando o ano de publicação, colocando em evidência primeiro os artigos, depois as dissertações e por fim as teses. Como critérios, focamos em cada um deles nos objetivos, nas fontes metodológicas utilizadas e nos resultados obtidos, por acreditarmos que as análises desses pontos trazem elementos importantes de contribuições e indícios norteadores para a compreensão e redefinição das categorias que envolvem a temática da história da Educação Física.

Seguindo essa proposta, inicialmente discutimos o estudo de Oliveira (2002), que trouxe algumas considerações sobre a história da Educação Física escolar no período da ditadura militar (1968-1984), objetivando a análise da dimensão social, política, econômica e cultural brasileira, sob a ótica de uma tradição de pesquisa comprometida com a transformação da Educação brasileira em geral e a Educação Física escolar em particular, a partir da década de 1980. Como outro objetivo importante do trabalho, o autor mencionou a questão das análises das práticas escolares, particularmente da Educação Física na história recente, a partir de um olhar para dentro da escola, devolvendo aos sujeitos o seu lugar nessa constituição histórica escolar.

O autor utilizou como fontes para análise documental, a série de 1968 a 1984 da Revista Brasileira de Educação Física e Desportos, os programas de Educação Física da Prefeitura Municipal de Curitiba entre 1970 e 1984 e, os depoimentos de professores da rede municipal de ensino de Curitiba. Para ele, a análise dos estudos permitiu constatar que a escrita na Educação Física tem sido à luz de determinantes estruturais, mas sem captar a lógica de processo impressa no desenvolvimento histórico. O autor ressaltou que a abstração e generalização atribuídas à história da Educação Física tem se derivado da ênfase nas discussões vinculadas as normativas governamentais. 
Com relação ao trabalho de Oliveira e Chaves Júnior (2009), percebemos que o estudo comparativo que realizaram, teve como foco os vários entendimentos e as diversas prescrições para Educação Física escolar na segunda metade da década de 1940 e na primeira metade dos anos 1970 do século passado no estado do Paraná. Como fontes para realização da pesquisa foram utilizados por esses autores, documentos oficiais, as Diretrizes para Educação Física nos estabelecimentos de Ensino Secundário de 1947, depoimentos de alguns professores escolares e alguns números da Revista Brasileira de Educação Física e Desportos dos anos 1970.

Apresentando os resultados, especificamente ressaltando a estrutura física da escola de ensino secundário, Oliveira e Chaves Júnior (2009) mencionaram que na década de 1950, a instituição escolar passou a ser configurada com a predominância de instalações direcionadas aos esportes. No entanto, as instalações não se concretizaram de fato nas escolas e couberam aos professores o poder de improvisação. Assim, na década de 1970 para os autores, o esporte era visto como algo avançado, como elemento modernizador das práticas escolares. Mas as condições reais para seu trabalho dentro da escola pareciam atualizar o velho descompromisso com a qualidade da instituição pública, manifestada pela carência e inadequação dos espaços para o desenvolvimento das aulas (Oliveira \& Chaves Júnior, 2009).

Colocando em evidência o trabalho de Bobassaro e Vaz (2009), notamos que seu objetivo foi investigar sobre as prescrições para a prática de Educação Física nas escolas catarinenses entre os anos de 1930 e 1940, destinadas aos docentes em geral, e talvez, a alguns egressos do recémcriado curso de formação de professores para a Educação Física, em 1938. Para isso, os autores supramencionados utilizaram como fonte documental, a legislação que criou e regulamentou a Escola de Educação Física, os relatórios do Departamento de Educação do Estado, no qual foram encontrados relatórios da Inspetoria de Educação Física, e especialmente, o periódico Revista de Educação (1936-1937).

Como principais resultados Bobassaro e Vaz (2009) encontraram três eixos que merecem destaque e estão articulados entre si: bases científicas das lições, controle das emoções ou disciplina moral, caráter lúdico pela prática de jogos. Finalizando as discussões sobre os resultados, os autores ressaltaram que as funções atribuídas à Educação Física para época era a modelagem do cidadão nacional, potencializando força física e disciplinando-o moralmente.

Trazendo o estudo de Rei e Ludorf (2012), os autores determinaram como objetivo discutir algumas funções atribuídas à Educação Física escolar no período da ditadura militar brasileira, sendo que utilizaram como fonte, um levantamento de estudos bibliográficos pautados em Betti (1991), Lino Castellani Filho (1988), Paulo Ghiraldelli Júnior (1988) se baseando como referencial de análise os trabalhos de Taborda de Oliveira (2001) e Rosa (2006).

O resultado apresentado por Rei e Ludorf (2012) foi que na legislação, a Educação Física escolar estaria a serviço da melhora da produtividade para o trabalho, da formação de atletas de alto rendimento e do uso político do esporte. No entanto, os dados demonstraram para os autores que a participação de alguns professores de Educação Física na elaboração das políticas públicas gestadas para a área e a presença de práticas pedagógicas heterogêneas, não necessariamente estavam alinhadas com os interesses do regime ditatorial-militar. 
Tendo como foco o trabalho de Góis Júnior et al. (2012), notamos que a finalidade foi analisar as influências dos debates sobre Educação Física dos anos 1980 no âmbito da Escola de Educação Física e Esporte (EEFE-USP), em específico, focando a análise no contexto histórico das reformas curriculares dos anos 1990 nessa instituição. Como fontes, os autores utilizaram as informações oriundas do método história oral de alguns professores antigos da referida escola.

Como resultados, constataram que os informantes têm visões diferentes sobre a formação profissional da escola, evidenciando que um grupo formado não desejava a separação entre Educação Física e esporte, contudo não se organizaram academicamente para esse debate. Os autores ainda enfatizaram que o contexto de debate dos anos 1980 na Educação Física brasileira influenciou a reforma curricular de 1992 na EEFE-USP.

Com relação à pesquisa realizada por Melo e Peres (2014), podemos detectar que visou investigar os sentidos e significados atribuídos ao corpo da nação pelo governo monárquico. Assim, foram utilizadas como fontes documentais, a legislação e os relatórios anuais do Ministério dos Negócios do Império (1831-1889), com especial interesse pelo que se refere ao Rio de Janeiro. Os autores abordaram que a ginástica chamava a atenção das autoridades, e era defendida no meio escolar, mas a sua implementação não avançava tanto quanto se esperava.

O resultado, que Melo e Peres (2014) apontaram, foi que as visões sobre a Educação Física se deram a partir de uma matriz que articulava concepções de moral, saúde e civilização, tendo que lidar com as condições concretas de um país recém-independente, periférico e ainda em formação.

Enfatizando os estudos de Dias (2014), percebemos que seu objetivo foi analisar os momentos iniciais do oferecimento de atividades de ginásticas, esportes e exercícios físicos em instituições escolares de Goiás. Para isso, o autor utilizou diversas fontes como legislações, jornais, fotografias, livros de memórias e documentos oficiais.

Como resultado de sua pesquisa, Dias (2014) sintetizando a história do início da Educação Física no estado de Goiás, enfatizou que no início, tratava-se de atividades difusas, mas mesmo assim apreendidas já como importantes, às vezes indispensáveis. Com o tempo, elas ganhariam relevância, adquirindo estatuto de um saber especializado no programa curricular das escolas de Goiás. Para finalizar, o autor abordou que o principal responsável por esse processo de implantação parece ter sido uma combinação de interesses civis e militares, nacionais e regionais.

Debruçando-nos sobre os estudos de Costa, Santos e Góis Júnior (2014), evidenciamos que o objetivo foi descrever o contexto de escolarização da Educação Física mediante o discurso médico do século XIX, sendo que como fontes foram utilizadas as teses de obtenção do título de doutor da Faculdade de Medicina do Rio de Janeiro e Bahia.

Os autores trouxeram como resultado, a argumentação de que a compreensão dos ideais dos médicos higienistas era movida mecanicamente pelos interesses dominantes, já que o projeto de nação proposto, embora em bases patrióticas, era muito crítico em relação à falta de intervenção governamental nos campos sociais, sobretudo, na educação. 
Sobre o estudo desenvolvido por Sá (2018), constatamos que o objetivo foi analisar as finalidades para a educação do corpo infantil que permearam a implantação da disciplina ginástica no ensino público primário mato-grossense na Primeira República. Para a realização da pesquisa, Sá (2018) utilizou fontes documentais localizadas no Arquivo Público do estado de Mato Grosso. A autora relatou que existiram grandes dificuldades de se implantar a disciplina de ginástica nas escolas, enfatizando motivos como preconceito, dificuldades financeiras de aquisição de materiais, entre outros.

Como resultado, Sá (2018) mencionou que os programas da disciplina de ginástica tinham como finalidade exercer uma influência moralizadora e higiênica que visava o desenvolvimento do corpo, da coragem e do patriotismo do futuro cidadão republicano, também sendo voltados para a formação da mulher e para o fortalecimento do seu corpo para o exercício da maternidade.

Com relação ao estudo proposto por Lyra, Mazo e Begossi (2018), teve como objetivo investigar as práticas e as representações culturais aferidas à área de conhecimento da Educação Física na formação de professores para atuar nas escolas primárias do Rio Grande do Sul. Como fontes foram utilizadas leis e relatórios expedidos no período, além de decretos e currículos oficiais de formação docente.

Como resultado, Lyra, Mazo e Begossi (2018) ressaltaram que o movimento de entrada da Educação Física foi sutil e lento no ambiente educacional. Eles constataram que a presença se deu não apenas de uma forma de ensinar Educação Física, mas sim de concepções variadas, provenientes de diferentes correntes de pensamento, que refletiam, justamente, a falta de um trabalho unificado e centralizado desde a preparação dos professores.

Mediante a análise dos artigos mapeados e selecionados, podemos constatar que sete deles se utilizaram de recortes temporais, delimitando o período a ser investigado, uma condição quase sempre presente quando se trata de estudos historiográficos (Oliveira, 2002; Bombassaro \& Vaz, 2009; Rei \& Ludorf, 2012; Góis Júnior et al., 2012; Dias, 2014; Lyra, Mazo \& Begossi, 2018; Sá, 2018). Foi interessante, no entanto, nos debruçarmos sobre os demais por se tratarem de estudos históricos que contribuem e enriquecem nossas discussões com indícios da trajetória e surgimento da Educação Física escolar brasileira.

Considerando os objetivos dos artigos científicos analisados, constatamos que as investigações feitas envolveram a procura da compreensão de sentidos e significados atribuídos ao corpo, das práticas e representações aferidas à área, das finalidades ou funções, da reconstituição dos momentos iniciais, das prescrições, da influência de áreas, da formação de acordo com contexto, colocando sempre em evidência a Educação Física escolar. Diante dos objetivos propostos nos estudos selecionados, percebemos que a (re)constituição da história da Educação Física tem abordado diversos aspectos desse componente curricular nas escolas.

Relacionado às fontes utilizadas nos estudos selecionados, um deles se utilizou de levantamento bibliográfico (Rei \& Ludorf, 2012) e os noves restantes de documentos oficiais e/ou institucionais como leis, decretos, diretrizes, currículos, relatórios, arquivos governamentais, programas, bem como revistas, livros, teses, fotografias e jornais. Relatos orais também foram utilizados em três deles (Oliveira, 2002; Oliveira \& Chaves Júnior, 2009; Góis Júnior et al., 2012) em 
associação com os documentos oficiais normativos, institucionais e pessoais, já assinalados. Também constatamos nos estudos selecionados para leitura e análises, que seis deles (Bobassaro \& Vaz, 2009; Costa, Santos \& Góis Júnior, 2014; Melo \& Peres, 2014; Dias, 2014; Sá, 2018; Lyra, Mazo \& Begossi, 2018) foram realizados tendo como fonte somente os documentos. Notamos, que ainda são poucas as pesquisas que utilizam relatos orais como fonte para (re)constituição histórica da Educação Física.

Analisando os principais resultados dos artigos científicos mapeados e selecionados nesse EQ, ficou evidente que a implantação da Educação Física nas escolas de educação básica se deu lentamente. A Educação Física estava vinculada, na maioria das vezes, aos ideais governamentais que buscavam a disciplinarização, a produtividade, a higienização e o patriotismo dos cidadãos, por meio da ginástica corporal, sendo no seu início influenciado pelos métodos de ginástica europeus (principalmente, alemão, sueco e francês), incorporando posteriormente, o esporte como conteúdo de destaque. Constatamos ainda que a dificuldade dessa implantação também teve associada ao preconceito e a questões financeiras dos alunos/famílias.

Outras constatações ainda pertinentes foram: a ocorrência de três pesquisas históricas sobre a Educação Física no período da ditadura militar (Oliveira, 2002; Oliveira \& Chaves Júnior, 2009; Rei \& Ludorf, 2012) e a ênfase de trabalhos nas regiões sul (Lyra, Mazo \& Begossi, 2018; Oliveira \& Chaves Júnior, 2009; Bombassaro \& Vaz, 2009; Oliveira, 2002), sudeste (Góis Júnior et al., 2012; Melo \& Peres, 2014) e centro oeste (Dias, 2014; Sá, 2018) do país. Percebemos assim, carência de pesquisas sobre a história da Educação Física na região norte e nordeste.

Com relação à análise das dissertações, iniciamos apresentando o estudo de Melo (1996) que estabeleceu como objetivo principal de sua pesquisa registrar uma das possíveis histórias da Escola Nacional de Educação Física e Desportos (ENEFD), primeira escola de formação de professores na Educação Física brasileira ligada a uma universidade. Para isso, utilizou documentos escritos e usou a história oral.

Como resultados do estudo, Melo (1996) elencou seis fatos sobre o trajeto histórico da ENEFD : 1- a criação da ENEFD estava ligada ao projeto político do Estado Novo (1937 a 1945); 2- o processo de criação da ENEFD não se diferenciou de outras escolas formativas em relação a presença central de militares; 3- a ENEFD obteve maior visibilidade no momento em que os médicos ocuparam a gestão; 4- a ENEFD teve um importante papel na produção e divulgação de novos conhecimentos; 5 - os estudantes ocuparam papel de destaque na estrutura da ENEFD; e 6a perda de status da ENEFD se deu tanto pela influência de fatores externos (mudanças de capital, reforma universitária, fusão do estado do Rio de Janeiro com o estado da Guanabara), quanto por fatores internos (lenta renovação do corpo docente, restrições ao movimento estudantil, afastamento dos médicos da direção).

Considerando a pesquisa de Campos (2007), notamos que está direcionada para a história da Educação Física ligada à dança, sendo que a finalidade de seu estudo foi problematizar as práticas de dança na formação de professores de Educação Física na Escola de Educação Física da Universidade Federal de Minas Gerais (UFMG), no período de 1952 a 1977. O autor utilizou como fontes para o levantamento de dados, as informações escritas, orais e iconográficas. 
Campos (2007) obteve como resultado a constatação que a dança se apresentava nas práticas de alunas e alunos por intermédio da atuação de professores com o intuito de diversificar conteúdos e estratégias de ensino. Além disso, a dança estava presente como tema das disciplinas Ginástica Rítmica, Danças, Rítmica e Recreação, demarcando espaço em cursos e eventos internos e externos à UFMG.

Trazendo as contribuições do estudo de Rodrigues (2009), ressaltamos que seu trabalho teve como objetivo analisar de que maneira a Educação Física se consolidou como disciplina escolar no Colégio de Aplicação da Universidade Federal de Pernambuco (UFPE) no período entre 1971 e 2001. Para realização da pesquisa o autor utilizou como fontes, os discursos produzidos nos documentos legais (LDB 5692/71, 9394/96, Lei 10328/2001) e nos documentos oficiais (PPP, Propostas Pedagógicas, Planos de ensino da disciplina, periódicos, livros, fotos) produzidos no referido colégio.

Os resultados apontados por Rodrigues (2009) demonstraram que existiam dois discursos referentes à Educação Física, um institucional e outro disciplinar. Inicialmente, esses discursos se aproximavam, mas com o tempo tiveram como principal vetor de divergência a manifestação e disputa por um poder que fez com que o processo de consolidação da Educação Física não se efetivasse. O primeiro polo focou na subvaloração dos corpos frente ao intelecto, estabelecendo para disciplina um papel meramente acessório (disforia). Já o segundo polo, caracterizado no início, por uma completa exclusão da disciplina na rotina, mas posteriormente, a partir da sistematização do conteúdo e de uma proposta pedagógica a Educação Física se insere ainda que timidamente, na organização interna (euforia).

Debruçando-nos sobre o estudo de Oliveira (2012), enfatizamos que teve como objetivo analisar parte da obra de Inezil Penna Marinho com a intenção de dar visibilidade à sua compreensão sobre a história da Educação Física no Brasil. As fontes utilizadas foram livros e artigos publicados entre os anos de 1940 e 1958 (tanto fontes primárias quanto secundárias) com viés de análise no âmbito da história cultural.

Como resultado, Oliveira (2012) destacou que a produção intelectual de Inezil Penna Marinho se deu com maior intensidade nos anos de 1940, sendo que seus trabalhos foram constituídos de maneira a se tornar testemunhos da área, perpetuando sua produção e sua inserção como autoridade na Educação Física brasileira.

Com relação ao estudo de Borel (2012), notamos que sua finalidade foi analisar a constituição da Educação Física escolar no Espírito Santo, nas décadas de 1930 e 1940. Essa autora utilizou como fontes os relatórios, recortes de jornais diversos, artigos publicados em revistas, pautas dos sujeitos, relatos e regulamentos.

Como resultado encontrado, Borel (2012) destacou que a formação dos professores de Educação Física no estado do Espírito Santo foi destaque em âmbito nacional, mesmo apresentando algumas dificuldades estruturais. Outro ponto relevante destacado pela autora, é que nas escolas capixabas a Educação Física mesmo passando por algumas adversidades, era desenvolvida e constantemente destacada nos meios de comunicação como revistas e jornais locais. 
Guimarães (2016) desenvolveu um estudo com o objetivo de compreender a configuração curricular da disciplina Educação Física no currículo mais amplo do Colégio de Aplicação da Universidade Federal de Sergipe (UFS) tendo como marco temporal o período de 1959 até 1996. Como fontes foram utilizadas as documentações, leis, atas da instituição, jornais, fotografias e história oral.

Os resultados obtidos com essa pesquisa foram que a Educação Física passa a ser vista como disciplina quando se sente a necessidade de professores específicos e preparados para organização e orientação de seu ensino. Em relação aos conhecimentos ensinados na Educação Física foram identificados a ginástica, esportes, conhecimentos relacionados à saúde e higiene, sendo ministrados através de aulas práticas e aulas teóricas, sem muitas vezes, apresentar uma continuidade.

No tocante as reflexões levantadas com a pesquisa de Pêgo (2016), destacamos que seu objetivo foi preservar a memória do processo de reestruturação curricular do curso de graduação em Educação Física da Faculdade de Ciências da Universidade Estadual Paulista "Júlio de Mesquita Filho" (UNESP), do campus universitário de Bauru, ocorrida em 1990. Para isso, se utilizou da revisão de literatura e de fontes documentais e história oral.

Pêgo (2016) ressaltou como principais resultados, que a reestruturação curricular aconteceu por meio da efetiva participação e responsabilidade do coordenador de curso, que ocorreu uma discreta participação dos estudantes nesse processo. Mencionou que os principais determinantes se caracterizaram pela urgência na concretização do novo currículo, devido ao prazo estipulado pela Resolução no 03 de 1987. Enfatizou ainda, que houve diminuição da carga horária das disciplinas prático-esportivas, sendo que atualização do currículo foi fruto de debates acadêmicos ocorridos a partir da década de 1980.

Considerando o estudo de Silva (2016) frisamos que sua finalidade foi analisar a relação entre currículo e história da Educação Física escolar no Brasil, no período entre o início da Primeira República (1889-1930) e o final da Era Vargas (1930-1945). As informações exploradas para realização do estudo foram obtidas a partir da pesquisa bibliográfica e de fontes primárias documentais.

Como resultado, Silva (2016) fez os seguintes apontamentos: o Compêndio gymnastica escolar desenvolvido por Arthur Higgins é um marco na história do currículo da Educação Física brasileira, por a obra apresentar características do tipo de elaboração curricular moderna, notadamente daquela fundamentada na teoria do Currículo Tradicional, que se desenvolvia nas primeiras décadas do século XX. Ainda afirmou que o Regulamento ( $\left.\mathrm{N}^{\circ} 7\right)$, que trata do método francês de ginástica foi produzido em relação de complementaridade à Revista da Educação Física, fato que de acordo com Silva (2016) desvela uma das formas através das quais o currículo da Educação Física brasileira se desenvolveu naquele período.

Colocando em evidências os estudos das cinco (5) Teses, começamos destacando a pesquisa de Sousa (1994) que estabeleceu como objetivo central construir a história do Ensino de Educação Física em Belo Horizonte, envolvendo questões políticas e socioculturais, procurando 
compreender a distinção entre as qualidades atribuídas à representação masculina e feminina. As fontes consultadas pela autora foram documentos escritos, orais e iconográficos.

Sousa (1994) ressaltou como resultados encontrados em relação ao tratamento de gênero nas aulas de Educação Física, a constatação de turmas separadas por sexo, conteúdos separados para homens e mulheres, professores para alunos e professoras para alunas, entre outras normas. Expôs também que as aulas de Educação Física com o propósito de coisificação do corpo, participam da construção social dos sujeitos masculinos e femininos. Por fim, destacou que a história construída, ao mesmo tempo mostra sinais de perpetuação das relações de gêneros hierarquizados, com dominação masculina, mas revela também lentas mudanças, nessas mesmas relações.

No tocante ao estudo de Anderáos (2005), percebemos que foram estabelecidos dois objetivos centrais, um procurando identificar os aspectos significativos que possam ter contribuído para as mudanças na formação profissional em Educação Física no Brasil e outro buscando coletar posicionamentos de coordenadores de cursos da área sobre contribuições do Conselho Federal e Regionais de Educação Física para a melhoria da formação profissional. Para o levantamento de informações foram utilizadas as seguintes estratégias: a pesquisa bibliográfica, a análise documental e a aplicação de questionários aos coordenadores de 28 cursos distribuídos pelo Brasil.

Os resultados encontrados pela Anderáos (2005) foram que a formação profissional na área de Educação Física sempre foi questionada e após anos de discussão e com a regulamentação da profissão, vive-se momento de impasse. Na legislação se promulgou a diferenciação entre as formações do licenciado e do bacharelado. Os conselhos passaram a fiscalizar o exercício profissional. Constatou-se ainda, que na percepção de alguns coordenadores dos cursos participantes da amostra, o Conselho Federal de Educação Física (CONFEF) e os Conselhos Regionais de Educação Física (CREFs) apresentam ações no sentido de contribuir para a capacitação profissional na área.

O trabalho de Pires (2007) teve como principal objetivo analisar a trajetória da formação profissional em Educação Física na Bahia, procurando recuperar uma das possíveis histórias dessa área de conhecimento nesse estado. As fontes utilizadas foram documentais e a realização de entrevistas.

Como resultado, Pires (2007) exaltou a existência de três momentos diferentes no decorrer da formação profissional da área, especificando que o curso da Universidade Católica foi o irradiador da formação em Educação Física na Bahia, o curso da Universidade Federal da Bahia foi um instrumento de mudança no perfil da formação e os cursos das Universidades Estaduais foram responsáveis pela interiorização do processo de formação em Educação Física no estado baiano.

Destacando a pesquisa de Rocha (2008), notamos que seu objetivo central foi compreender a gênese e desenvolvimento da Educação Física escolar em Fortaleza, entre o intervalo de tempo de 1860 a 1930. A autora supramencionada utilizou diversas fontes, tais como literatura, fotografia, periódicos escolares, jornais, trabalhos acadêmicos, documentos oficiais e obras de memorialistas. Apresentou a autora como resultado, a existência de práticas corporais 
nas escolas de Fortaleza, frisando que os passos iniciais foram dados como ginástica em algumas instituições educacionais, até chegar à denominação de Educação Física, perpassando pelos embates entre os agentes - acrobatas (os ginastas "marginais"), os instrutores (militares) e as normalistas, que contribuíram para o movimento de naturalização e objetivação da prática dessa disciplina na escola.

Com relação ao trabalho de Ventura (2010), destacamos que seu objetivo foi promover uma investigação sobre a luta pelo monopólio do pensamento na área da Educação Física, partindo do pressuposto de que o coletivo mais amplo não se apropria das ações que envolvem as contradições inerentes aos objetivos dos intelectuais hegemônicos e contra hegemônicos, e as consequências que possam emanar. As fontes utilizadas foram os anais do Simpósio Internacional de Ciências do Esporte e do Congresso Brasileiro de Ciências do Esporte, de 1987 a 2009.

Os resultados constatados por Ventura (2010) evidenciaram que as contradições de um movimento no interior da Educação Física brasileira, só se manifestam de forma mais concreta a partir dos anos de 1980, com acirramento na segunda metade dos anos 2000 nos diversos espaços das relações sociais de trabalho (produção do conhecimento, formação profissional, intervenção pedagógica), por influência incontestável das atuais diretrizes curriculares.

Mediante ao que encontramos no inventário realizado com as dissertações e teses, podemos constatar que há ausência de lócus investigativos que abordem municípios do interior do nordeste, especialmente do estado do Ceará. No entanto, estudos realizados tendo como foco o estado cearense, encontramos a tese desenvolvida por Rocha (2008) que se propôs a constituir a história da Educação Física escolar na capital (Fortaleza), no período de 1860 a 1930.

Com relação à similaridade com título de nossa dissertação de mestrado, podemos destacar a pesquisa de Borel (2012) intitulada "Processos de formação e práticas docentes na constituição histórica da Educação Física escolar no Espírito Santo, nas décadas de 1930 e 1940 ". Entretanto, o período de tempo investigado é outro, o lócus é diferente e seu conteúdo embora traga contribuições a nossas reflexões, dar ênfase na formação inicial a partir das Instituições de Ensino Superior Capixaba.

Considerando os objetivos das teses e dissertações selecionadas, percebemos que seis delas são pesquisas que se encontram vinculadas a estudos relacionados à história da Educação Física com foco nas instituições de ensino superior, tais como o estudo de Melo (1996) que buscou registrar uma das possíveis história da ENEFD, o de Campos (2007) que focou na problematização da prática da dança na Escola de Educação Física da UFMG, o de Rodrigues (2009) que analisou a consolidação da Educação Física como disciplina no Colégio de Aplicação da UFPE, o de Guimarães (2016) que investigou a configuração curricular da Educação Física no Colégio de Aplicação da UFS, o de Pêgo (2016) que procurou preservar a memória da reestruturação curricular desse curso na UNESP, e o de Pires (2007) que analisou a trajetória da formação profissional na Bahia com foco nos cursos superiores.

Notamos que dois trabalhos apontam para historicidade em municípios, como o de Sousa (1994) que se empenhou na construção da história do ensino da Educação Física em Belo Horizonte-MG e o da Rocha (2008) que focou na gênese de desenvolvimento da Educação Física 
em Fortaleza-CE. Numa abrangência federativa maior, a pesquisadora Borel (2012) se empenhou na constituição da Educação Física no Espírito Santo.

Ainda temos quatro trabalhos com olhares diversos na historicidade voltados para a Educação Física, como o de Oliveira (2012) que teve como referência a história dessa disciplina a partir de um olhar do Inezil Penna Marinho, o de Silva (2016) que analisou o currículo e história da Educação Física no Brasil em dois períodos (início da primeira República e final da Era Vargas), o de Anderáos (2005) que focou em aspectos que contribuíram para as mudanças profissionais nessa área no Brasil, e finalmente o de Ventura (2010) que se preocupou em investigar a luta pelo pensamento ideológico na Educação Física ao longo do tempo. Em síntese, podemos constatar que os objetivos dessas pesquisas permeiam o campo da história da Educação Física com foco em registro, compreensão, análise, reconstituição envolvendo currículo, formação e elementos da prática docente em meio escolar.

No tocante ao uso das fontes de informações, evidenciamos que um estudo ressalta revisão de literatura e fontes primárias (Silva, 2016), os demais se utilizaram de documentos diversos (leis, decretos, diretrizes, artigos, anais, projetos políticos pedagógicos, atas, planos de aulas, relatórios, jornais, fotos, entre outros) para levantamento de seus dados, sendo que seis (Melo, 1996; Campos, 2007; Guimarães, 2016; Pêgo, 2016; Sousa, 1994; Pires, 2007) do total de treze se utilizaram também de relatos orais.

Em relação aos resultados das pesquisas provenientes das teses e dissertações mapeadas e selecionadas, podemos identificar apontamentos importantes a respeito da história da Educação Física, destacando currículo, formação e prática docente. Sobre as questões curriculares, foi frisado que a Educação Física passa ser vista como disciplina quando sentem a necessidade de docentes específicos para orientarem e organizarem o ensino (Guimarães, 2016), que a obra Compendio de Higgins é um marco na história do currículo da Educação Física brasileira (Silva, 2016), que presenciou-se turmas separadas por sexo, conteúdos diferenciados para ensinar homens e mulheres, professores para alunos e professoras para alunas (Sousa, 1994).

Referindo-se a formação, julgamos ser significativo destacar que o estado do Espírito Santo foi um dos primeiros a conceber formação em Educação Física no âmbito da sociedade civil servindo de modelo para os demais (Borel, 2012); a criação da ENEFD esteve ligada ao projeto político do Estado Novo (1937-1945) ressaltando-se a presença central de militares (Melo, 1996); ao longo dos anos a legislação alterou-se exigindo uma diferenciação entre as formações do licenciado e do bacharelado (Anderáos, 2005).

Enfatizando as práticas docentes, podemos notar nesses trabalhos acadêmicos analisados, que os métodos de ginástica europeus serviram de referências para o início da Educação Física em meio escolar, constando também ao longo dos anos, esportes, danças e conhecimentos relacionados à saúde e higiene vinculados aos ideais dos militares e médicos. Especificamente, no município de Fortaleza o surgimento da Educação Física em meio escolar decorreu de embates entre os agentes de ginástica acrobata, os instrutores militares e as normalistas. 


\section{CONSIDERAÇÕES FINAIS}

O inventário dessas produções foi importante para percebermos o que vem sendo pesquisado sobre a história da Educação Física com ênfase na formação e prática docente, até o momento da data de busca nos bancos de dados acessados. Nessas produções foi possível conhecer os autores, o objetivo maior de seus estudos, as fontes utilizadas e os resultados alcançados que contribuiu para recondução e/ou validação do objeto de investigação de nossa pesquisa de mestrado, bem como nos enriqueceu de conhecimento para a fundamentação dos argumentos e nos auxiliou nas análises dos achados no campo documental e empírico.

Neste sentido, podemos destacar que uma das grandes contribuições de nosso EQ é a riqueza dos olhares nos textos analisados que nos ajudaram a conhecer outras realidades e as maneiras de investigá-las. Além disso, nos permitiu constatar como principal lacuna, a ausência de municípios do interior usado como lócus das produções científicas no campo historiográfico da Educação Física no Ceará.

Diante disso, as constatações do nosso EQ nos fortalecem na argumentação da necessidade de investigação da história da Educação Física na região nordeste, especialmente nos municípios interioranos do Ceará, para registros das especificidades locais e valorização da identidade histórica de um povo e ainda para evitar a generalização de informações constatadas em outros contextos.

Dessa forma, ao realizar o EQ, percebemos o quão rico foram às contribuições trazidas e as reflexões levantadas a respeito da história da formação e prática do professor de Educação Física nas diversas partes do Brasil, utilizando-se das mais variadas fontes, com uma variedade enorme de objetivos e uma diversidade de resultados alcançados, e mesmo diante desse cenário, ainda encontramos a lacuna supramencionada que nossa pesquisa de mestrado procurou supri-la. Diante disso, recomendamos o uso do EQ nas pesquisas científicas, para sobretudo, situar o pesquisador sobre o que já existe em relação ao seu objeto de investigação, ajudando-o a delimitá-lo e a detectar as contribuições mais incisivas de sua produção científica.

\section{REFERÊNCIAS}

Anderáos, M. (2005). A reorganização da formação profissional em Educação Física no Brasil: aspectos históricos significativos (Tese de Doutorado). Faculdade de Educação Física, Universidade Estadual de Campinas, Campinas, SP, Brasil.

Bombassaro, T., \& Vaz, A. F. (2009). Sobre a formação de professores para a disciplina Educação Física em Santa Catarina (1937-1945): ciência, controle e ludicidade na educação dos corpos. Educar em Revista, (33), 111-128. https://doi.org/10.1590/S0104-40602009000100008

Borel, T. (2012). Processos de formação e práticas docentes na constituição histórica da Educação física escolar no Espírito Santo, nas décadas de 1930 e 1940 (Dissertação de Mestrado). Universidade Federal do Espírito Santo, Vitória, ES, Brasil. 
Campos, M. A. A. (2007). Histórias entrelaçadas: presença da dança na Escola de Educação Física da UFMG (1952-1977). (Dissertação de Mestrado) Faculdade de Educação, Universidade Federal de Minas Gerais, Belo Horizonte, MG, Brasil.

Costa, L. H. DA, Santos, M DE S, \& Góis Junior, E. (2014). O discurso médico e a Educação Física nas escolas (Brasil, século XIX). Revista Brasileira de Educação Física e Esporte, 28(2), 273-282. https://dx.doi.org/10.1590/1807-55092014000200273

Dias, C. (2014). Momentos iniciais da educação física em Goiás (1917-1929). Revista Brasileira de Educação Física e Esporte, 28(1), 95-111. https://dx.doi.org/10.1590/S1807$\underline{55092014000100095}$

Góis Junior, E. et al. (2012). Estudo histórico sobre a formação profissional na Escola de Educação Física e Esporte da Universidade de São Paulo (1980-1990). Motriz: Revista de Educação Física, 18(2), 393-400. https://dx.doi.org/10.1590/S1980-65742012000200019

Guimarães, M. A. (2016). Um olhar sobre a história da organização curricular da educação física no colégio de aplicação da universidade federal de Sergipe (1959-1996) (Dissertação de Mestrado). Universidade Federal de Sergipe, São Cristóvão, SE, Brasil.

Lyra, V. B., Mazo, J. Z., \& Begossi, T. D. (2018). A educação física no currículo da formação de professores primários no Rio Grande do Sul (1877-1927). Revista Brasileira de Educação, 23, e230040. Epub July 26, 2018. https://doi.org/10.1590/s1413-24782018230040

Melo, V. A. DE. (1996). Escola Nacional de Educação Física e Desportos: Uma possível história (Dissertação de Mestrado). Faculdade de Educação Física, Universidade Estadual de Campinas, Campinas, SP, Brasil.

Melo, V. A. DE, \& Peres, F. DE F. (2014). O corpo da nação: posicionamentos governamentais sobre a educação física no Brasil monárquico. História, Ciências, Saúde-Manguinhos, 21(4), 11311149. https://doi.org/10.1590/S0104-59702014000400004

Nóbrega-Therrien, S. M. \& Therrien, J. (2004) Os trabalhos científicos e o estado da questão: reflexões teórico-metodológicas. Estudos em Avaliação Educacional, 15(30), 5-16. Recuperado de: http://www.fcc.org.br/pesquisa/publicacoes/eae/arquivos/1203/1203.pdf.

Oliveira, A. S. F. (2012) Inezil Penna Marinho: História e Educação Física (1940 a 1958) (Dissertação de Mestrado). Centro de Educação Física e Desportos, Universidade Federal do Espírito Santo, Vitória, ES, Brasil.

Oliveira, M. A. T. DE. (2002). Educação Física escolar e ditadura militar no Brasil (1968-1984): história e historiografia. Educação e Pesquisa, 28(1), 51-75. https://dx.doi.org/10.1590/S1517$\underline{97022002000100004}$

Oliveira, M. A. T. DE, \& Chaves Junior, S. R. (2009). Os espaços para a educação física no ensino secundário paranaense: um estudo comparativo entre os anos finais da ditadura varguista e os anos da ditadura militar brasileira pós 1964. Educar em Revista, (33), 39-56. https://dx.doi.org/10.1590/S0104-40602009000100004 
Pêgo, P. L. DOS S. (2016) A história da graduação em Educação Física da UNESP de Bauru e memória da reestruturação curricular de 1990 (Dissertação de Mestrado). Instituto de Biociências, Universidade Estadual Paulista "Júlio de Mesquita Filho", Bauru, SP, Brasil.

Pires, R. G. (2007). História da Educação Física na Bahia: O percurso da formação profissional (Tese de Doutorado). Universidade Federal da Bahia, Salvador, BA, Brasil.

Rei, B. D., \& Lüdorf, S. M. A. (2012). Educação física escolar e ditadura militar no Brasil (19641985): balanço histórico e novas perspectivas. Revista da Educação Física / UEM, 23(3), 483497. https://doi.org/10.4025/reveducfis.v23i3.15221

Rocha, A. M. (2008). Educação Física Escolar: História da inserção e consolidação na capital cearense (Tese de Doutorado). Faculdade de Educação, Universidade Federal do Ceará, Fortaleza, CE, Brasil.

Rodrigues, J. R. DE B. (2009). A Educação Física como disciplina escolar - Que história é essa?: A construção componente escolar Educação Física no Colégio de Aplicação da Universidade Federal de Pernambuco no período de 1971 a 2001 (Dissertação de Mestrado). Universidade Federal de Pernambuco, Recife, PE, Brasil.

Sá, E. F. DE. (2018). A Educação dos corpos infantis no Projeto Mato-Grossense de formação do cidadão republicano (1910-1930). Cadernos CEDES, 38(104), 75-88. https://doi.org/10.1590/cc0101-32622018178353

Silva, R. N. DA. (2016). Currículo escrito e a história da Educação Física no Brasil (1896-1945) (Dissertação de Mestrado). Universidade Federal de São Carlos, Sorocaba, SP, Brasil.

Sousa, E. S, DE. (1994). Meninos, à Marcha! Meninas, à sombra! A história do ensino da Educação Física em Belo Horizonte (1897 - 1994). (Tese de Doutorado). Faculdade de Educação, Universidade Estadual de Campinas, Campinas, SP, Brasil.

Ventura, P. R. V. (2010). A Educação Física e sua constituição histórica: desvelando ocultamentos (Tese de Doutorado). Pontifícia Universidade Católica de Goiás, Goiânia, GO, Brasil.

\section{COMO CITAR ESTE ARTIGO:}

Lima, P. R. DE, Nóbrega-Therrien, S. M. (2020). Estudos sobre a história da formação e prática docente de educação física: o estado da questão. Holos. 36(6), 1-20.

\section{SOBRE OS AUTORES}

\section{P. R. DE LIMA}

Doutorando do Programa de Pós-Graduação em Educação (PPGE) da Universidade Estadual do Ceará (UECE). Professor da Secretaria de Educação do Estado do Ceará (SEDUC).

E-mail: progerio.sport@gmail.com

ORCID ID: https://orcid.org/0000-0002-2323-4008

\section{S. M NÓBREGA-THERRIEN}

Doutora em Sociologia da Educação, pela Universidade de Salamanca, Espanha e Pós-Doutora em Educação pela Universidade de Valencia, Espanha. Professora Assistente da Universidade Estadual do Ceará do Programa de Pós-Graduação em Educação e do Curso de graduação em Medicina. Líder do Grupo de 
Pesquisa Educação, História e Saúde Coletiva e Coordenadora do Laboratório- LEHSC.

E-mail: silnth@terra.com.br

ORCID ID: https://orcid.org/0000-0002-9660-8314

Editor(a) Responsável: Francinaide de Lima Silva Nascimento Pareceristas Ad Hoc: Alison Batista e Ednaldo Coutinho

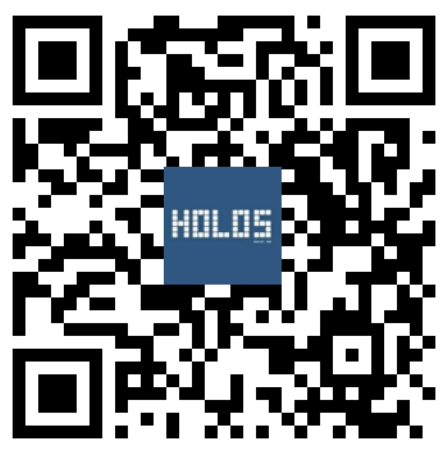

